\title{
Analysis of the level of stress in teachers
}

\section{Análisis del nivel de estrés en los profesores}

\author{
MARTÍNEZ-ESPARZA, Dora Esthela†*, PÉREZ-ESQUIVEL, María Mayela and BRAVO LÓPEZ, \\ Tamara
}

Universidad Autónoma de Nuevo León

Universidad Regiomontana de Monterrey

Instituto Politécnico Nacional (Mexico City)

ID $1^{\text {st }}$ Author: Dora Esthela, Martínez-Esparza / ORC ID: 000-0002-2531-4204

ID $1^{\text {st }}$ Co-author: María Mayela, Pérez-Esquivel / ORC ID: 0000-0002-0275-7571

ID $2^{\text {nd }}$ Co-author: Tamara, Bravo-López / ORC ID: 0000-0002-2992-2629

DOI: $10.35429 /$ JET.2021.13.5.20.27

Received March 14, 2021; Accepted June 30, 2021

\begin{abstract}
This research aims to know the stress level of teachers of one of the Santa Catarina Technological University majors and, if it is high, take the appropriate measures to try to reduce it to a safer proportion for teachers, and thus prevent teachers from getting sick or incapacitated very often. It is known to all that if the teacher does not fulfill his obligations, the one directly affected is the student, who will have a poor academic performance. To measure the level of stress, a questionnaire consisting of 23 questions will be applied to the teachers of the cited school, the options that will have to answer those questions are 4: nothing at all, a little, moderately and strongly, with values of 1, 2, 3 and 4 respectively; The answers selected by the teachers will be added and compared with a low, medium and high scale. Subsequently, a relationship of the level of stress against teacher performance will be established through a statistical treatment, where the correlation of these variables will be established by the method of the linear correlation coefficient $r$ of Pearson. Likewise, the equation of the regression line by least squares will also be established with its corresponding graph for analysis.
\end{abstract}

Stress, Analysis, Performance

\begin{abstract}
Resumen
La presente investigación pretende conocer el nivel de estrés de los profesores de una de las carreras de la Universidad Tecnológica Santa Catarina y, en caso de resultar alto, tomar las medidas convenientes para tratar de disminuirlo a una proporción más segura para los maestros, y de esa forma evitar que los docentes se enfermen $\mathrm{o}$ incapaciten con mucha frecuencia. Por todos es sabido que si el maestro no cumple con sus obligaciones el directamente afectado es el alumno, quien tendrá un pobre rendimiento académico. Para medir el nivel de estrés se aplicará a los maestros de la escuela citada un cuestionario consistente en 23 preguntas, las opciones que tendrá que contestar esas cuestiones son 4: nada en absoluto, un poco, moderado $\mathrm{y}$ fuertemente, con valores de 1, 2, 3 y 4 respectivamente; se sumarán las respuestas seleccionadas por los maestros y se cotejarán con una escala de bajo, medio y alto. Posteriormente se establecerá una relación del nivel de estrés contra el desempeño docente a través de un tratamiento estadístico, donde se establecerá la correlación de estas variables por el método del coeficiente de correlación lineal $\mathrm{r}$ de Pearson. Así mismo también se establecerá la ecuación de la recta de regresión por mínimos cuadrados con su correspondiente gráfica para su análisis.
\end{abstract}

Estrés, Análisis, Desempeño

Citation: MARTÍNEZ-ESPARZA, Dora Esthela, PÉREZ-ESQUIVEL, María Mayela and BRAVO LÓPEZ, Tamara. Analysis of the level of stress in teachers. Journal Educational Theory. 2021. 5-13: 20-27

\footnotetext{
* Correspondence to Author (e-mail: demartinez@utsc.edu.mx)

$\dagger$ Researcher contributing as first author.
} 


\section{Introduction}

The concept of stress was first introduced to the field of health in 1926 by Hans Selye. At present, it is one of the most used terms. Selye defined stress as the body's overall response to any stressful stimulus or stressful situation. The concept of work stress according to the World Health Organization is defined as "the physiological, psychological and behavioral response of an individual who tries to adapt and adjust to internal and external pressures", prevailing disorders such as headaches, episodes of anxiety, hypertension and psychosomatic diseases such as colitis, irritable bowel syndrome among others. Work stress appears when there is a mismatch between the person, the job and the organization itself. (Yang $\mathrm{X}, \mathrm{Ge}$ C, Hu B, Chi T, Wang L., 2009).

Never before have teachers been subjected to such intense, complex, and sometimes contradictory demands from the administration, students, parents, and society at large. Faced with these pressures, many teachers suffer an alarming increase in stress, which can affect their good performance in the classroom.

The most diverse sources agree that, in recent years, the responsibilities and demands that are projected on teachers have increased, coinciding with a historical process of a rapid transformation of the social context, which has resulted in a modification of the role of the teacher, which is an important source of discomfort for many of them, since they have not known, or simply have not accepted, to accommodate themselves to the new demands.

\section{Theoretical Framework}

Stress, anxiety, tension, burnout and neurosis are some of the terms used to denote the negative aspects of modern life. The expression "being under stress," or "being in a state of stress," usually indicates a dangerous situation that borders on exhaustion. It is difficult to address a phenomenon as widespread as stress and establish its problems among teaching professionals, without first defining it generically. According to numerous experts, stress is an adaptive response to an external stimulus.
The "subject" with which teachers work, human beings in full growth, allows a very small margin of foresight and therefore its management exposes these professionals to considerable doses of stress.

Stress can lead an individual to the situation of exhaustion and consequently develop pathogenic effects. The most common symptoms among teachers are a feeling of exhaustion and frustration or extreme tension. For some, stress would cause, directly or indirectly, in the development of serious organic effects such as hypertension, heart disease, migraines, ulcers, asthma, gallbladder diseases and kidney diseases. On the mental level, permanent stress can lead to depression and general anxiety. (Esteve, 1987).

Some professions, such as teachers, are exercised by people with a great vocation and who, according to this, set high expectations that sometimes creates great frustration among teachers; there are also the administrative or organizational barriers that these education professionals often encounter, consequently causing a higher level of stress.

More and more teachers are suffering from work stress. This is not only a personal psychological problem, but a social problem. One of the causes is that society has changed, but not the training that teachers receive. In addition, the family delegates more and more responsibilities to the school and disregards its responsibility to its children. Teachers also believe that the social prestige of their profession has declined. Education experts relate teacher discomfort with the deterioration of the social image of the teacher and point out as the main problems of current teaching the lack of motivation on the part of students and teachers, the growing disinterest of parents, the excessive number of students per class and the lack of attention of the school authorities.

The teacher feels overwhelmed as a source of authority and knowledge in the face of an increasingly challenging student. Teachers have to teach some students who arrive at school without rules or values instilled in the family and other types of students who correct them in the middle of the class for having an Internet connection. 
A long-term effect of stress among teachers is complete emotional exhaustion. This state can lead to an attitude of apathy outside of school generating a number of defensive strategies. This type of burnout can be identified as a type of chronic response to the negative, cumulative, and long-term impact of work stress. (Cooper, 1997). If the teacher presents an important level of stress he will begin to use a defense system that makes him believe that he can eliminate the origin of these tensions, he will begin to be absent to the work place, to get sick or incapacitated, to ask for more and more prolonged leave, not to perform well in classes, etc.; causing a very poor quality performance of their work which affects the students and the institution. A high level of stress in teachers can cause them to literally "burn" with the work they do, reaching burnout syndrome.

Burnout, is an Anglo-Saxon term whose closest translation is "to be burned", worn, exhausted and lose the illusion of work. The studies of Maslach and Jackson (1981, 1985 and 1986) defend that Burnout is a three-dimensional syndrome that develops in those professionals whose object of work are people (users) and add three characteristic dimensions. The first one is the feeling of not being able to give more of oneself to others.

Depersonalization is the second dimension and is understood as the development of feelings, attitudes, negative, distant and cold responses towards other people, especially towards the beneficiaries of one's own work. It is accompanied by an increase in irritability and a loss of motivation towards it. The professional tries to distance himself not only from the people targeted by his work but also from the members of the team with whom he works, being cynical, irritable, ironic and even sometimes using derogatory labels to allude to users and trying to make them guilty of their frustrations and decreased work performance.

A third dimension consists of a feeling of low achievement or low professional fulfillment and that arises when the demands that are made exceed their ability to attend them competently. It involves negative responses towards oneself and towards work, neglecting personal and professional relationships, poor work performance, inability to withstand pressure and low self-esteem.
Lack of personal achievement at work is characterized by painful disappointment and failure to make give personal meaning to work. Feelings of personal failure (lack of competence, effort or knowledge), lack of expectations and horizons at work, and widespread dissatisfaction are experienced. As a consequence, unpunctuality, frequent interruptions, the avoidance of work, absenteeism and abandonment of the profession are common and typical symptoms of this occupational pathology.

As for the symptoms, they can be grouped into four areas:

a) Psychosomatic.

1. Headaches

2. Chronic fatigue

3. Ulcers or gastrointestinal disorders

4. Muscle aches in the back and neck

5. Hypertension and in women lost menstrual cycles.

b) Behavioral:

1. Absenteeism

2. Violent behavior

3. Drug abuse

4. Inability to relax

c) Emotional:

1. Affective distancing that the professional manifests to the people he serves

2. Desires to quit work

3. Irritability

4. Difficulty concentrating due to anxiety experienced

5. He doubts his professional competence, with the consequent decrease in self-esteem.

d) Defensive:

1. Denial of emotions.

2. Irony

3. Selective attention

4. Displacement to other situations or things.

By work performance we mean the ability of workers, in our case of education, to be able to efficiently perform the work they do in the classroom, fulfilling satisfactorily the following features:

- Good punctuality and assistance.

- Be in constant training.

- $\quad$ Prepare the class in advance. 
- Be constantly monitoring whether students are really learning

- Know if students are satisfied with their work as a teacher.

- $\quad$ Try to maintain a cordial relationship with other teachers.

- $\quad$ Respect the authority of the school.

\section{Methodological framework}

A brief description of the type of research to be carried out shall be included in the research methodology. It will include the techniques and strategies used in the study, as well as the characteristics, size and shape in which the population was selected. It also describes the instrument used for data collection and the procedures that will be used to organize and analyze the statistically obtained data.

\section{Type of Research}

This study can be considered as a descriptive study because it aims to show a phenomenon by studying from its characteristics.

The instrument used for data collection will provide descriptive information on the stress level of teachers.

\section{Population and sample}

It took the total of the universe that are 30 teachers in the Industrial Processes major, who participated voluntarily.

\section{Instrument}

An opinion poll that was prepared for data collection will be used. In this instrument, the teacher will be presented with a questionnaire of 23 questions with space to answer them. It will be used to collect data that has to do with the stress level of teachers.

The questionnaire will be applied to the teachers in a personal way. Each option that the teacher has to answer the 23 questions has the following values:
a) nothing at all $=1$ point
b) a little $=2$ points
c) moderate $=3$ points
d) $\quad$ strongly $=4$ points

The options selected by each of the teachers will be added according to the given score. This score will be related to the scale described below.

\section{Stress level scale}

1- 65 low stress level

66-117 average stress level

118-172 high stress level

Finally, information was collected from teachers about their level of teaching performance in this period that the survey was applied to measure the level of stress.

The aspects considered for the level of teaching performance are evaluated in each school period at the Santa Catarina Technological University, and are the following:

a) Teacher Performance: based on a survey of evaluation of the teacher's actions by their students, which is applied by the Planning Department and has a weighting of $40 \%$.

b) Capture of qualifications and attendance in a timely manner, with a weighting of $20 \%$.

c) Punctuality and attendance, which consists of covering your scheduled academic load without delays or faults, weighting $30 \%$.

d) Teacher updating, which requires assistance and proven participation in at least one course of pedagogy, education or technological update during the period evaluated. Its weighting is $10 \%$.

\section{Results}

Once the survey has been applied, the statistical processing of the data obtained is carried out. Here it is presented that in any distribution of data it can be visualized if they relate to each other. And with this assertion events can be predicted with a good degree of acceptance, this being one of the main practical applications.(Pagano, 2006) 
This technique is simple to perform and with these correlation studies you can check the correlation between two variables and it is the first thing that has to prove their relationship if it is casual or not. Correlation and regression are very interrelated where the former indicates the magnitude and direction and in regression can use the relationship to predict a case.

Next, the calculations made in this case are presented, obtaining the data that are: level of stress as an independent variable and teaching performance as a dependent variable of the group of teachers interviewed, a survey was obtained according to the following table 1 Results of the level of stress and table 2 Results on the level of teaching performance.

\begin{tabular}{|c|c|c|}
\hline Teacher & Score obtained & Stress level \\
\hline 1 & 72 & Middle \\
\hline 2 & 86 & Middle \\
\hline 3 & 87 & Middle \\
\hline 4 & 69 & Middle \\
\hline 5 & 62 & Low \\
\hline 6 & 50 & Low \\
\hline 7 & 49 & Low \\
\hline 8 & 58 & Low \\
\hline 9 & 62 & Low \\
\hline 10 & 90 & Middle \\
\hline 11 & 118 & High \\
\hline 12 & 78 & Middle \\
\hline 13 & 120 & High \\
\hline 14 & 71 & Middle \\
\hline 15 & 80 & Middle \\
\hline 16 & 79 & Middle \\
\hline 17 & 73 & Middle \\
\hline 18 & 75 & Middle \\
\hline 19 & 55 & Low \\
\hline 20 & 119 & High \\
\hline 21 & 52 & Low \\
\hline 22 & 81 & Middle \\
\hline 23 & 82 & Middle \\
\hline 24 & 64 & Low \\
\hline 25 & 53 & Low \\
\hline 26 & 89 & Middle \\
\hline 27 & 49 & Low \\
\hline 28 & 84 & Middle \\
\hline 29 & 96 & Middle \\
\hline
\end{tabular}

Table 1 Results of the level of stress in teachers Source: Own Elaboration

\begin{tabular}{|c|c|}
\hline $\begin{array}{c}\mathrm{X}=\text { Stress } \\
\text { level }\end{array}$ & $\begin{array}{l}\mathrm{Y}=\text { Teaching } \\
\text { performance }\end{array}$ \\
\hline 72 & 89.56 \\
\hline 86 & 88.73 \\
\hline 87 & 95.07 \\
\hline 69 & 83.73 \\
\hline 62 & 86.82 \\
\hline 50 & 79.33 \\
\hline 49 & 74.68 \\
\hline 58 & 82.06 \\
\hline 62 & 90.98 \\
\hline 90 & 83.72 \\
\hline 118 & 89.21 \\
\hline 78 & 88.35 \\
\hline 120 & 79.85 \\
\hline 71 & 91.47 \\
\hline 80 & 93.87 \\
\hline 79 & 88.70 \\
\hline 73 & 91.64 \\
\hline 75 & 87.49 \\
\hline 55 & 95.28 \\
\hline 119 & 91.56 \\
\hline 52 & 92.67 \\
\hline 81 & 87.91 \\
\hline 82 & 80.43 \\
\hline 64 & 84.38 \\
\hline 53 & 90.14 \\
\hline 89 & 92.72 \\
\hline
\end{tabular}

Table 2 Results on the level of teaching performance Source: Own Elaboration

The following is the correlation calculation by means of the r-Pearson equation

$$
\begin{aligned}
& r(1)=\frac{\sum x y-\frac{\left(\sum x\right)\left(\sum y\right)}{N}}{\sqrt{\left[\sum x^{2}-\frac{\left(\sum x\right)^{2}}{N}\right]\left[\sum y^{2}-\frac{\left(\sum y\right)^{2}}{N}\right]}} \\
& =\frac{201430.50-\frac{(2285)(0.01282639 .04)}{30}}{\sqrt{\left[185405-\frac{(2285)^{2}}{30}\right]\left[232863.08-\frac{(2639.04)^{2}}{30}\right]}} \\
& r=\frac{201430.50-201006.88}{\sqrt{(185405-174040)(232863.08-232151.07)}}= \\
& \frac{423.62}{\sqrt{(11364.17)(712)}}=\frac{423.62}{2844.51} \\
& r=0.1489
\end{aligned}
$$

The value of the correlation factor indicates a weak positive relationship, which means that stress does not have a considerable impact on teacher performance, which could be because human psychology behavior is unpredictable.

The calculation of the linear regression equation is presented below.

$$
\begin{gathered}
b y(2)=\frac{\sum x y-\frac{\left(\sum x\right)\left(\sum y\right)}{N}}{\sum x^{2}-\frac{\left(\sum x\right)^{2}}{N}}=\frac{201430.50-\frac{(2285)(2639.04)}{30}}{185405-\frac{(2285)^{2}}{30}} \\
b y=\frac{201430.5-201006.88}{185405-174040.83}=\frac{423.68}{11364.17}=0.0372
\end{gathered}
$$

MARTÍNEZ-ESPARZA, Dora Esthela, PÉREZ-ESQUIVEL, María Mayela and BRAVO LÓPEZ, Tamara. Analysis of the level of stress in teachers. Journal Educational Theory. 2021 
$A y(3)=\bar{Y}-b x(\bar{X})=87.968-(0.0372)(76.16)=$ $87.968-2.8331=85.13$

Ecuación Lineal: $Y^{\prime}(4)=$ byX $+A y=$

$Y^{\prime}=0.0372 X+85.13$

The data obtained are presented in the following graph 1 of dispersion.

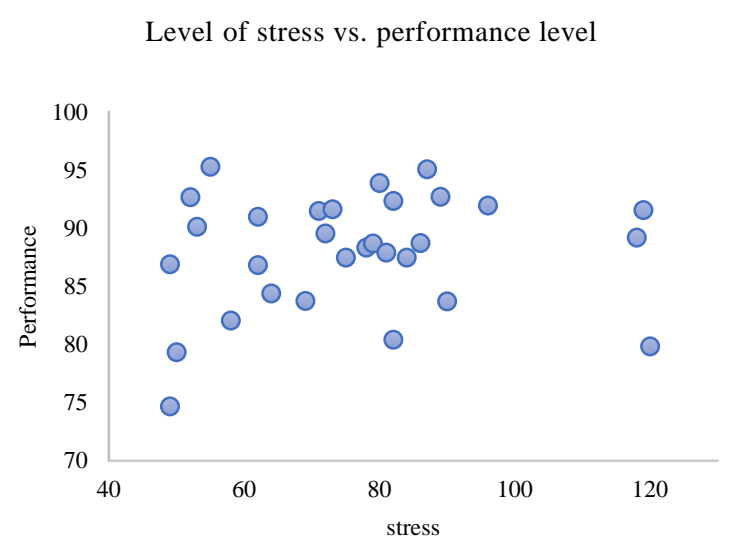

Graph 1 Scatter plot

Source: Own elaboration

In the following graph 2 histogram of performance with distribution curve shows the behavior of the impact variable that is performance, yielding the value of the mean of 87.968 with a minimum of 74.68 and a maximum of 95.28 , with a standard deviation of 5.04 .

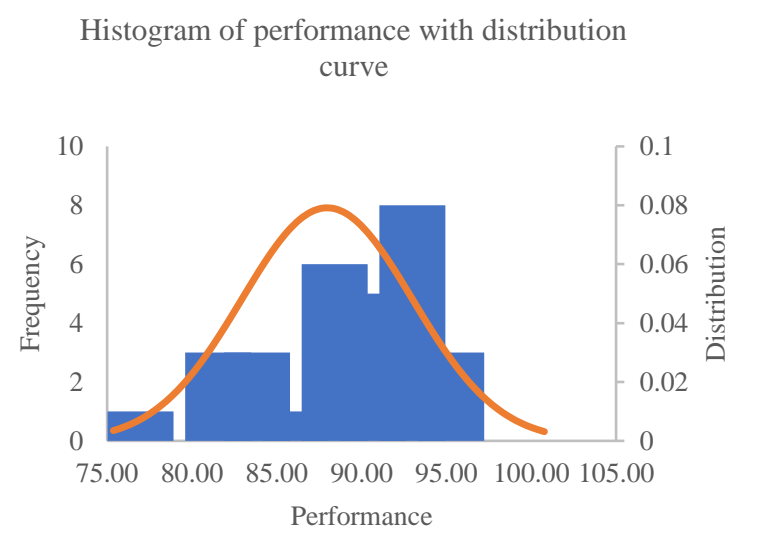

Figure 2 Performance histogram with distribution curve Source: Own elaboration

It should be noted that the survey and the results of Teacher Performance Level were carried out at the beginning of 2020 , considering the last evaluation applied to teachers, which was the one corresponding to the month of December 2019, at that time, the COVID-19 pandemic was not yet present, which came to considerably alter the working conditions of the population.
And in particular of the teaching staff, with great changes in all areas and as is well known, adaptation to changes in usual activities, together with the fear of contagion, isolation and everything that the pandemic has generated in society are factors that contribute to the increase of stress in all people.

In a study conducted at the National University of Asunción, (Gómez Dávalos \& Rodríguez Fernández, 2020)a survey using the Perceived Stress Scale (PSQ) developed by Levenstein was applied to 37 teachers during the quarantine period due to the COVID-19 pandemic. They responded with a 4-point Likert scale $(1=$ "almost never" $2=$ "sometimes" $3=$ "often" $4=$ "almost always")

The results obtained in the 3 standardized factors, in terms of the percentage of teachers who manifested perception of 3 and 4, were the following:

1. Tension and exhaustion $67 \%$

2. Overload on tasks, perception of lack of time and external demands $74 \%$

3. Frustration, hopelessness, fear of the future $78 \%$.

According to these results, most teachers experience significant levels of stress. It is mentioned that they are preliminary results, so additional studies are required to complement these findings.

There are, however, antagonistic positions to the previous one, because in the article entitled "TheBurnout Syndrome and its effect on teaching performance in times of pandemic", the authors conclude that the fact of having less personal (Espinoza Izquierdo, Moran Peña, \& Granados Moreno, 2021)contact with students in times of pandemic is a factor that decreases the emotional wear and tear that can lead to chronic stress or burnout. And that the fact that teachers have become more trained in the use of digital technologies and tools increases teachers' personal satisfaction in meeting new challenges.

It would be interesting to delve into these 2 aspects, but in our institutional context, the perception is that the current pandemic has caused an increase in work stress in teachers. 


\section{Conclusions}

Based on the questionnaire applied to 30 teachers of the Industrial Processes major at this University, it is concluded that $10 \%$ of teachers suffer from a high level, $57 \%$ a medium level of stress and 33\% have a low level of stress, giving a percentage of $67 \%$ of the total of teachers with the most accentuated problem.

This research is of vital importance because it allows us to identify the extreme cases of teachers affected by stress at a certain level and thus giving rise to take the most appropriate measures to be able to attend to those teachers on time, before the problem becomes more complicated and can affect the academic performance of students and the school. If the problem is not addressed in a timely manner, the time will come when the teacher gets tired or does not perform in his work and begins to miss or incapacitate, reaching to suffer, in the worst case, the Burnout syndrome.

On the other hand the results should also be considered the average of years in front of group that oscillates between an average of 13.9 years, the average age is 36.7 years, in addition to the total number of respondents 15 are men and 15 are women, of which men manage stress better because they resulted in lower averages, it is worth mentioning that the Institution has a permanent training program where important issues such as personal and professional development are addressed, which includes motivational courses, among others.

Finally, a Pearson r-method correlation of the results of the stress level as an independent variable with respect to teacher performance was made, an indicator that is measured at the end of each period (Sanchez, 2019) for each teacher in an institutional way and it was found that there is a low correlation between these variables, since the result was 0.1489 for teacher performance, this indicator includes several factors, including a survey that is applied to students on the performance of the teacher each period, so it is concluded that the stress factor in teachers is decisive to obtain the desirable results but also other factors such as motivation and compliance with results come into play.
The value of $\mathrm{r}$ obtained is 0.1489 which indicates that there is a weak positive correlation between the two variables, which refutes the initial hypothesis and indicates that the level of stress does not affect the performance of teachers.

These results reflect that, although there is a medium or high level of stress in most of the teachers in the sample analyzed, their professional performance is not negatively affected because this indicator determines their permanence in the institution, taking into account that the higher the educational level of the teacher, the greater the prevalence to work even with health affectations.

With the COVID-19 pandemic, the way teachers work radically changed, adapting to teaching online classes demanded a large investment of time, in technology training, material preparation, extended hours of attention to students and a long etcetera.

We have conducted an informal survey and it is perceived that the degree of stress increased by approximately $45 \%$ compared to how teachers felt before the pandemic, however, a new study would be required to determine the effect of this extraordinary stressful situation on the level of teacher performance.

This obviously differs from the results of research mentioned at the Paraguayan (Gómez Dávalos \& Rodríguez Fernández, 2020) University, where the percentages were around $70 \%$ of teachers with a high level of perceived stress, since since that study has passed approximately a year and obviously with the massive vaccination campaigns in our country and the slow return to activities in the new normal, affect the self-perceived level of stress in the educational setting.

However, as has already been reiterated, new studies are required to complement the current ones and the contexts in each country are varied.

\section{References}

Abraham, A. (1984). The eseñante is also a person. Spain: Gedisa.

Abraham, A. (1987). The inner world of teachers. Spain: Gedisa. 
Cooper, C. L. (1997). The stress of teachers. Pressure on teaching activity. Spain: Paidos.

Espinoza Izquierdo, J. G., Moran Peña, F. L., \& Granados Moreno, J. F. (March 2021). Burnout Syndrome and its effect on teacher performance in times of pandemic. Obtained from polodelconocimiento.com:

https://polodelconocimiento.com/ojs/index.php/ es/article/view/2395/4901

Esteve, J.M. (1987). Teacher discomfort. Spain: Laia.

Gómez Dávalos, N. R., \& Rodríguez Fernández, P. (September 09, 2020). Stress in teachers in the context of the covid-19 pandemic and education, fenob UNA - Filial Coronel Oviedo. Obtained from

https://revistascientificas.una.py/ojs/index.php/r fenob/article/view/150

Hernández, R., Fernández, C., \& Baptista, P. (2014). Research methodology. Mexico: McGraw-Hill.

Jersild, A. T. (1986). The personality of the master. Spain: Paidos.

Orlandini, A. (1999). Stress, what it is and how to avoid it. Mexico: Fondo de Cultura Económica.

Pagano, R. R. (2006). Statistics for the behavioral sciences. Mexico: Thomson.

Sanchez, E. (August 28, 2019). The stress scale, according to Holmes and Rahe. Obtained from The Stress Scale, according to Holmes and Rahe: https://lamenteesmaravillosa.com/la-escala-delestres-segun-holmes-y-rahe/

Yang $\mathrm{X}$, Ge C, Hu B, Chi T, Wang L. . (November 2, 2009). Public Health. Retrieved from Public Health: http://dx.doi.org/10.1016/j.puhe.2009 